\title{
Regaining A Sense Of Me: a single case study of SCl adjustment, applying the appraisal model and coping effectiveness training
}

\author{
J. Duff ${ }^{1} \cdot$ B. Angell ${ }^{1}$
}

Received: 1 September 2020 / Revised: 9 October 2020 / Accepted: 12 October 2020

(C) International Spinal Cord Society 2020

\begin{abstract}
Introduction Sustaining a spinal cord injury (SCI) has been shown to impose a significant physical and psychological challenge with threat to quality of life (QOL). Duff \& Kennedy provide a SCI explanation of appraisals and the two-stage process of an individual's primary assessment of their experience, and their secondary appraisal of their perceived coping resource being key facilitators of adjustment and fundamental to longer term adaptation. King \& Kennedy designed a group coping effectiveness training (CET) intervention with a framework of coping strategy selection fit to reduce use of threat appraisals/avoidance coping, and to promote development of challenge appraisals with consequent stress reduction and adjustment.

Case presentation This CET approach was applied within individual psychological therapy with a 74-year old woman who presented with symptoms of anxiety, reactivated PTSD, mood disturbance and difficulty adjusting after sustaining SCI. Psychological adjustment treatment enabled resolution of post-trauma symptoms, re-evaluation of appraisals and perceived loss of identity, and development of positive coping strategies, and promoted a new conceptualisation of independence.

Discussion Case studies of psychological treatment are rare within the SCI literature. This paper provides a detailed application of primary appraisals and coping strategy selection fit in individual therapy. Attention is drawn to the important impact appraisals have on long-term rehabilitation outcomes and the necessity of a multi-disciplinary team (MDT) approach to achieve optimal psychological and physical adjustment following SCI. Finally, the paper highlights the need for community education to reduce negative perceptions/taboo of disability.
\end{abstract}

\section{Introduction}

Sustaining a spinal cord injury (SCI) has been shown to impose significant physical and psychological consequences [1]. In some instances, research has evidenced a reduction in quality of life (QOL), with around 35\% of patients experiencing depression [1,2], alongside a higher likelihood of anxiety and an increased risk of suicide [3,4].

Contemporary explanatory models of psychological adjustment following SCI were built on an understanding that successful coping and adjustment is a product of interactions between a person and their environment [5].

$\triangle$ J. Duff

bht.nsicpsychology@nhs.net

1 NSIC Clinical Psychology Department, National Spinal Injuries Centre, Stoke Mandeville Hospital, Buckinghamshire Healthcare NHS Trust, Aylesbury, UK
Over time, researchers have considered the role of coping strategies, applying Folkman and Lazarus's Transactional Model of Stress and Coping [5], and developing more advanced adjustment models formulated on individual response [6]. This led to the evolution of coping models that focused on the individual's preferential coping style and recognised bespoke personal adjustment.

Duff and Kennedy [7] provided an SCI-specific translation of the Transactional Model (Fig. 1), suggesting SCIspecific examples of threat, loss and challenge (primary appraisals) and perceived resources available for coping (secondary appraisals [5]). They recognise from general psychological research, the influence of pre-injury psychological factors (e.g., emotional history, social support, selfefficacy etc.) but make specific reference to disability beliefs about self-world schema adjustment from cognitive therapy, which can influence preferred coping styles. Folkman et al. suggested that problem-focused coping strategies find best fit with situations appraised to be 'changeable' and emotion-focused strategies to situations 


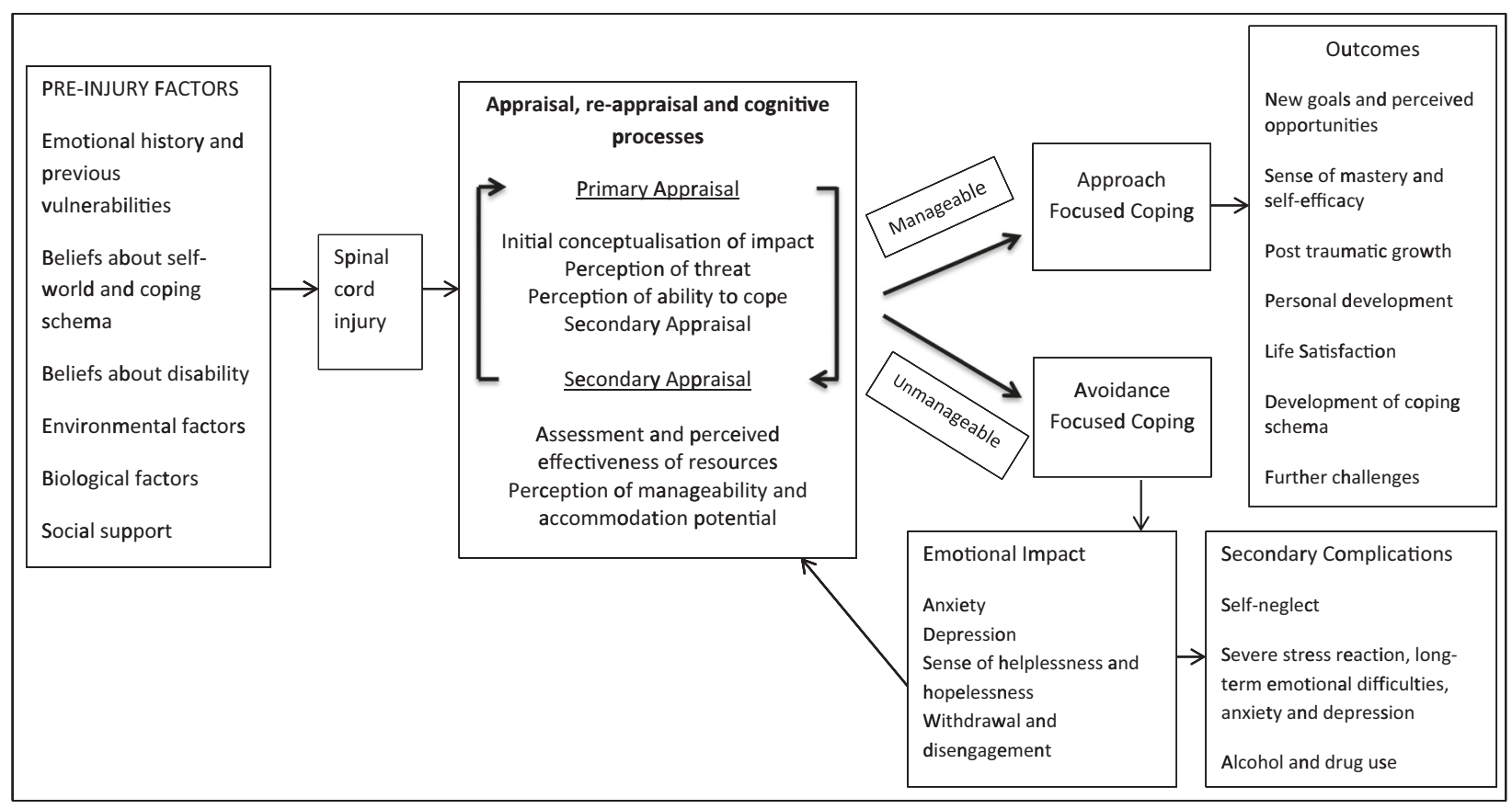

Fig. 1 SCI Appraisal Adjustment Model (based on transaction model of stress and coping [8]), Duff and Kennedy [7].

appraised to be 'unchangeable' [8]. Contemporary research has criticised the stringent categories of emotion and problem-focused coping, questioning their conceptual clarity [9]; Duff and Kennedy's model therefore advances these suggesting that beliefs about 'manageability' develop from appraisal-coping strategy fit. 'Manageability' develops through use of approach strategies (e.g., thinking about how to cope and problem solve), or negatively develops an avoidance framework, with hypothesised detrimental adjustment outcome, from beliefs that SCI is "unmanageable'. This conceptualisation was developed further through coping effectiveness training (CET) [10-12], with Kennedy's longitudinal research endorsing the association between avoidance, poorer adjustment and mood state [13].

Additionally the SCI Adjustment Model [14], based on Duff and Kennedy, adds to research knowledge of the fluidity and non-linear process of adjustment within developing self-efficacy beliefs after SCI.

Appraisal-based models within SCI research have indicated associations and predictions between early coping strategies after injury and long-term coping [13]. Evidence also highlights negative appraisals as key predictors of mood [15] and shows their significant impact on coping [16]. The use of avoidance-focused coping strategies were found to be significant predictor of mood, stress and QOL at 12 weeks and 1 year post injury, and contributed significantly to the variance in these outcomes at 2 years post injury [17].

Although there is limited comparative research into psychological treatment, it is recognised that addressing psychological health and adjustment impacts on rehabilitation outcome [7]. Cognitive Behavioural Therapy (CBT) is an evidence-based structured intervention for anxiety and depression [18, 19], however, SCI-specific applications of effectiveness are less conclusive [20-22]. Dorstyn et al. [23], in a meta-analysis of CBT efficacy for adults with SCI, suggested a significant positive impact on short-term psychological factors (mood); however, these benefits were not sustained 2 years after SCI and suggested the need for specific therapeutic interventions focusing on short, medium and long-term adjustment.

King and Kennedy designed the brief, structured group intervention, $\mathrm{CET}$, to teach practical appraisal skills and a stress management toolkit within SCI rehabilitation [10]. A crucial component of CET is the re-evaluation of appraisal and coping strategy fit - whether the impact of a stressor was reduced. CET amalgamates psychological appraisal theory and CBT, providing a framework that individuals can utilise to reduce threat appraisals and development of avoidance coping strategies [24]. CET has been shown to reduce depression, anxiety and psychological distress [12], through providing a group space in which individuals can consider potential stressor reactions whilst focussing on practical problem-focussed strategies to promote wellbeing. By reducing perceived demand and consequent stress, the intervention aims to improve an individual's actual and perceived control [25]. Components of the intervention include psychoeducation, goal directed action/goal planning [26], problem solving, reconnection with values and social support work [24]. 
This case report details the psychological adjustment intervention provided to an inpatient during SCI rehabilitation with psychological formulation from Duff and Kennedy [7]. CET was applied as direct individual treatment rather than in-group therapy, as previously published.

\section{Case presentation}

Theresa, a 74-year old woman, sustained a complete C5-C6 SCI, following a fall in March 2017. She was admitted to a local hospital where she underwent initial acute surgery and spinal stabilisation, and admitted to SCI rehabilitation 2 months after injury.

Theresa was referred to the clinical psychology team the day following admission with trauma symptoms, high levels of anxiety and difficulties coping. A comprehensive psychological assessment revealed Theresa experiencing symptoms of reactivated PTSD including anxiety at night and nightmares and difficulty coping without her family close. Routine psychological screening measures for mood and adjustment were completed: the short form of the Appraisals of DisAbility Primary and Secondary Scale (ADAPSSsf) [27], the Hospital Anxiety and Depression Scale (HADS) [28] and the Perceived Manageability Scale (PMnac) [29].
The ADAPSS is an SCI specific, 33 item self-report measure with demonstrated robust psychometric properties [27]. The short form is one of the quality indicators for psychological wellbeing on the NHS England SCI dashboard, assessing six appraisal subsets and providing a structure for a clinical interview about adjustment and areas for psychological treatment. Each subset has a normal, upper/lower and high/low distress range. The HADS [28] is a 14 item self-report measure of symptoms of anxiety and depression [30]. The PMnac [29] is a validated SCI-specific scale based on the theory of planned behaviour, and measures an individual's beliefs about perceived control. It comprises five items measured via a four-point Likert scale. The scale is on the UK National dashboard as an outcome measure for psychological intervention and is used in QOL research [31].

Theresa scored above the recommended clinical threshold of 22 on the ADAPSSsf, and therefore, the full scale was completed. Her ADAPSSsf profile showed adjustment difficulties, with all three subscales in the high distress range for the loss/'catastrophic negativity' domain [27]. In terms of the 'resilience' domain, two subscales were in a positive direction. She was within the upper normal range for determined resolve and growth and resilience, but the low range for personal agency (Fig. 2). Theresa scored above clinical caseness (16) on HADS anxiety and

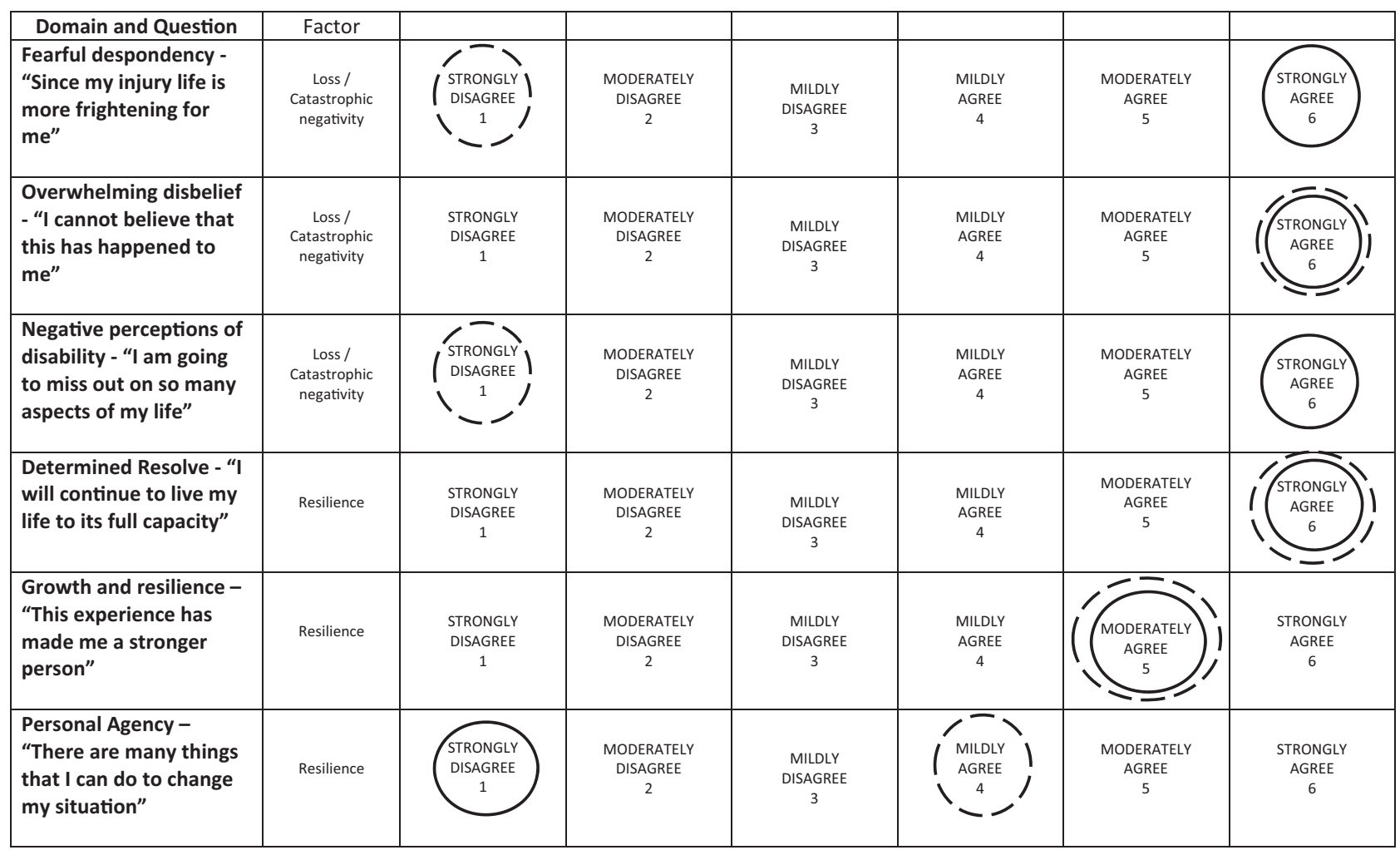

Fig. 2 ADAPPS-sf admission (solid line) and discharge (dotted line). 
Table 1 Perceived manageability PMNac admission and discharge.

\begin{tabular}{|c|c|c|c|c|}
\hline & Not at all & Sometimes & Fairy often & Almost always \\
\hline Situation manageable & & & Discharge & Admission \\
\hline Skills to cope & & Admission & Discharge & \\
\hline Rewarding activities & & Admission and discharge & & \\
\hline Social support & & & & Admission and discharge \\
\hline Motivated to engage & & & & Admission and discharge \\
\hline
\end{tabular}

borderline caseness (9) HADS depression. Her outcome measures reflected her clinical interview self-report, indicating that both her primary and secondary appraisals of her current situation made it feel 'unmanageable' (Table 1; PMnac) [7].

Prior to sustaining an SCI, Theresa was an extremely active individual: hobbies were daily swimming, social connection with friends and family, reading, and attending church, and she took great pleasure in baking. Theresa provided care for her grandchildren and was considered to be the 'matriarch' and 'go to' person by her grown up children and family system, offering regular support. For Theresa, her SCI represented a catastrophic loss of this active contributing lifestyle, with her self-identity and perceived role within the family shifting dramatically. Theresa saw her identity move from a predominantly independent care provider to being dependent and cared for. Her family remained a strong support system, visiting the hospital regularly and providing active care. Theresa felt in great need and appreciative of such support, but recognised it compounded her perceived identity shift and psychological distress.

The NSIC Stoke Mandeville SCI Psychological Health and Wellbeing Matched Care Intervention Pathway (Table 2) outlines standard care to be psychological therapy every 2-3 weeks for mood/adjustment difficulties without presentation of active suicide risk [32]. Theresa attended psychological treatment aligned with this; the main intervention used was individualised CET, specifically the components of psychoeducation, problem solving, identity reconstruction and social support $[24,25]$. This collaborative intervention aimed to facilitate reappraisal and shift her perception towards one of 'manageability', activate approach-focused coping strategies and increase her sense of control.

Relevant medical history included a period of intubation in an intensive care unit (ICU) 20 years earlier in which Theresa recalled being unable to speak or cry but 'inside was screaming'. These traumatic memories were reactivated following SCI surgery prior to rehabilitation and were appraised by Theresa as an ongoing threat and she requested the constant presence of a family member, predominantly her daughter, during SCI rehabilitation.

A key component of the initial psychological intervention was treatment of Theresa's reactivated trauma symptoms and acute distress. This included reframing her traumatic memories to associate them as 'past' and for her to develop a current sense of safety and symptoms quickly resolved [33]. In relation to Theresa's acute adjustment distress, intervention focused on discussion about challenges, with sessions enabling exploration of her perceptions of her ability to cope and a focus on primary appraisals, centreing on threat and loss such as, 'I am not the same person as I used to be' and 'I can't look after my grandchildren any more'. Theresa and her clinical psychologist established a strong therapeutic collaborative alliance from the initial assessment, possibly enhanced by the therapist first seeing her shortly after admission at a very vulnerable stage, whilst still on bed rest to discuss the reactivated trauma memories, and later in her rehabilitation maintaining therapeutic contact during brief ICU regressions. This therapeutic alliance enabled Theresa to be open about her greatest fears, be tearful at times, and provided space to explore her self-doubt whilst maintaining confidence in her therapist's ability to receive and hold her strong emotion, without being overwhelmed by it, and to maintain a framework of unconditional positive regard which is central to therapeutic work. During sessions, sensitive exploration identified her values of being a good mother/grandmother/friend and discussed how to reconnect with this and regain a sense of ability. Through acknowledgement of her initial sense of perceived loss and graded CET approach, Theresa was able to connect with different aspects of the stressors, and develop small problem-solving coping actions to test out her negative beliefs, such as sending letters and cards to loved ones to maintain a social connection. This enabled re-evaluation of her appraisals and beliefs about 'manageability' and connected her with the value behind the action, even though the mechanism to achieve the outcome was different (e.g., through initially dictating letters to her daughter and then using voiceactivated software). In time, she reconnected with other values, such as re-establishing the perceived lost role of collecting her grandchildren from school, and attending school concerts and family engagements. For a significant part of Theresa's individual psychological treatment her daughter (her main support in hospital) was also provided with independent counselling support. In the latter stages of Theresa's admission this became joint work with Theresa and her clinical psychologist and involved mutually- 


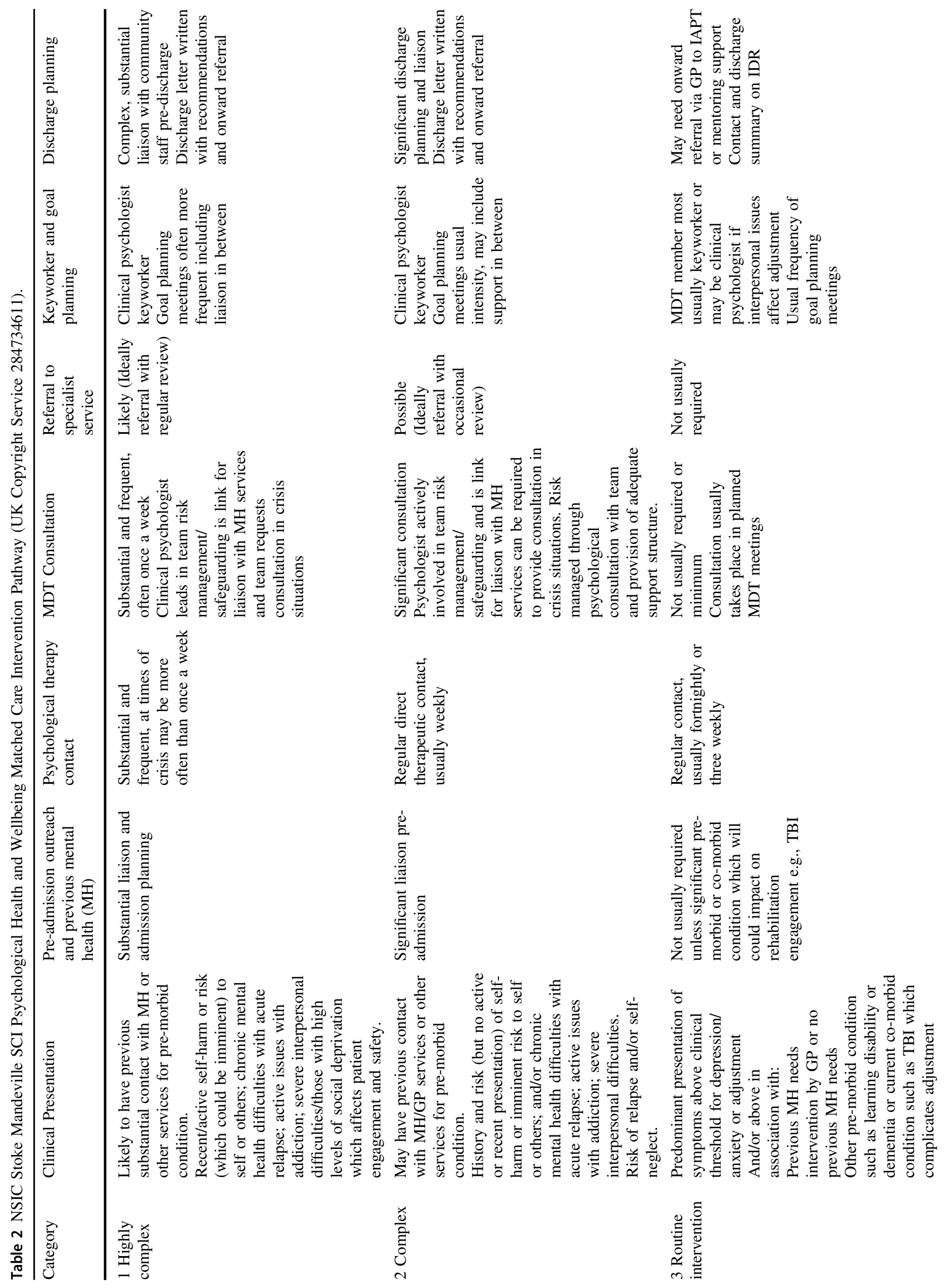




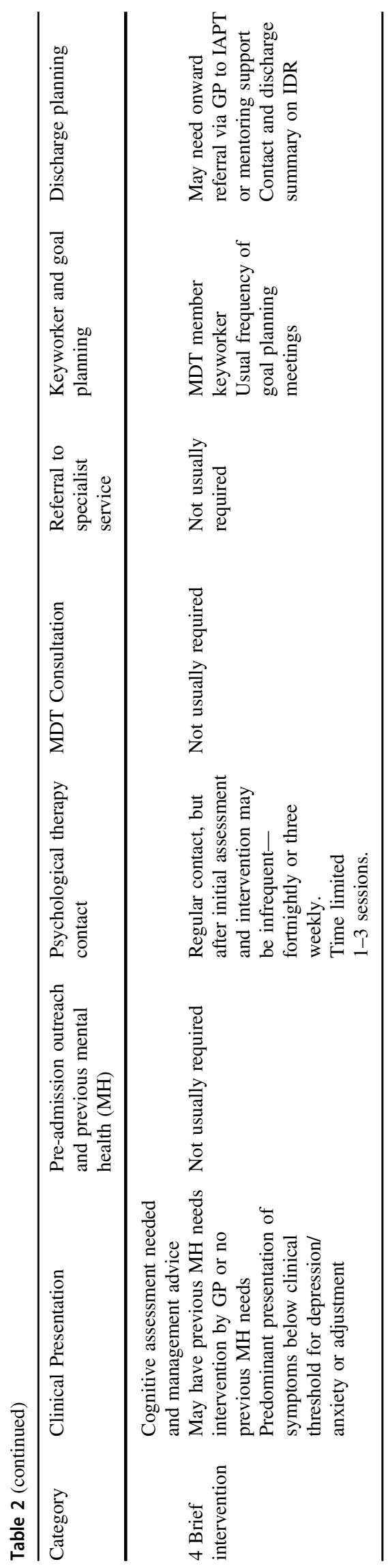

negotiated goal setting between Theresa and her daughter to enable her daughter to have time away from hospital. This involved explicit naming and recognition of the potential of carer strain and the importance of self-care. It served the dual purpose of supporting her daughter to emerge from the inpatient hospital phase and regain her own sense of personhood as well as increasing Theresa's independence. It is a testament to the strength of Theresa, her daughter and her wider family structure that Theresa was able to have the sustained support she did and also that the system was flexible enough to cope with the changed relationship dynamics as she progressed towards discharge, and to facilitate her regaining her sense of self.

A central feature of CET is appraisal and coping strategy fit, so psychological treatment also focused on development of this and approach-focused coping strategy development. Regular mindfulness sessions were used to reduce anxiety symptoms [34], and therapy connected her behaviourally with skills of using a tablet to access mindfulness apps and develop a sense of self-care and compassion. Taught CBT mood-management strategies coupled with CET were continuously revisited throughout Theresa's rehabilitation, aimed at increasing her perceived ability to cope. Behavioural activation (BA), commonly considered a third-wave therapy stemming from CBT, recognises the importance of changing behavioural patterns that may be positively reinforcing depression or anxiety [35]. For Theresa's treatment, BA was used to integrate a sense of self e.g., looking like 'old self' (applying makeup, setting hair, wearing colourful clothes) and engaging in activity scheduling (setting aside 'non hospital' time to read books or watch films). Psychoeducation enabled her to identify how to use strategies to elevate her mood and reduce the impact of prolonged hospitalisation.

Promotion of Theresa's independence and control was an ongoing theme throughout her psychological treatment sessions. Intervention included empowering her to feel comfortable and confident in expressing her needs through verbal instruction to the ward and therapy team. This piece of work included goal setting in sessions with Theresa and her daughter and then the inclusion of these within multidisciplinary team (MDT) goal planning which in turn increased her sense of control enough for her to be alone, without her family, in hospital for a few hours and then a day. This fed into the collaborative work on identity shift, changing identification with the 'dependent' role adopted since injury and reclaiming behaviours and activities associated with her 'old' identity.

Overall, working flexibly by employing strategies from multiple psychological models and therapeutic approaches such as CET, CBT and BA enabled Theresa to adapt her selfworld beliefs and thought processes (cognitions) around her injury, regain important elements of independence and 
control, reclaim activities in line with her values and identity, learn mood-management strategies to build resilience and maintain wellbeing, and develop a belief that SCI could be 'manageable' [7].

On discharge, following this regular psychological intervention, Theresa's ADAPSSsf score had reduced to 14 (Fig. 2), with scores on fearful despondency and negative perceptions of disability scales decreasing. This indicated disengagement from cognitions around catastrophic negativity and loss and an increased sense of manageability (Table 1). Theresa's HADS scores reduced to 6 (below clinical caseness for anxiety) and to 2 (normal range for depression).

\section{Discussion}

Although many studies analyse the effectiveness of theories and models across patient populations, this paper seeks to provide a rare in-depth exposition and application of an adjustment-specific model and its connected intervention. It outlines how a psychological model of appraisals and coping strategy fit can be applied within a physical health setting [7, 11, 24, 25]. Application of core themes from the group CET intervention (stressors after SCI, the development of appraisal-coping fit and effective coping strategies to promote long-term health and wellbeing) are interpreted and applied to an individual's psychological treatment with therapeutic exploration of identity. In a study analysing avoidance and approach-focused coping at 12 week and 21year follow-up, Kennedy et al. found that positive reinterpretation of the injury 12 weeks post SCI predicted $37.2 \%$ of variance in depression at 21 plus years [13]. This demonstrates how early rehabilitation can be a predictor of long-term adjustment and the importance of early intervention. This case study also draws healthcare professionals' attention to the potential of re-traumatisation years after ICU admission. In the current climate of the COVID19 pandemic it is, now more than ever, paramount that we understand both the immediate psychological impact of ventilation/life support and the long-term effects this has on psychological adjustment following future hospital admissions. In a multi-centre study analysing the risk of developing mental health difficulties following discharge from ICU, Hatch et al. found that over half the participants reported significant symptoms of anxiety, depression or PTSD and that, when symptoms of such psychological disorders were present, there was a $65 \%$ chance that they would co-occur with one of the other two disorders [36]. Kennedy et al.'s findings suggested that psychological factors such as depression and coping ability may contribute to premature mortality after SCI [13]. In addition, during the COVID-19 pandemic, many inpatients have been denied access to loved ones. In Theresa's case, her inability to have family present during her earlier hospital admission may have contributed to her symptoms of trauma, and activated her security for her family to be present continuously during her SCI rehabilitation. This highlights the impact that being denied social connectedness may have on a patient's ability to cope and recover. An understanding of how this isolation may also influence a patient's presentation or reactions to staff in rehabilitation settings is valuable. Gillet et al. offer insight into psychological implications of isolation within infection-control settings in SCI and the potential barriers to social connectedness [37]. Overall, the significance of acknowledging previous health episodes and maintaining awareness that previous experiences can impact on patient's psychological adjustment is essential and may serve as an interesting topic for future research.

This case report emphasises the significance of recognising the influence that appraisals have on behaviour, mood, adjustment and, in turn, rehabilitation outcome. Theresa initially experienced a number of threat appraisals and perceived a significant loss, in her sense of control and identity, which led to avoidance-focused coping and development of low mood and anxiety. This presentation supports the findings of Kennedy et al. [38], who found use of avoidancefocused strategies to be associated with poor mental health, and Kennedy et al. [15], who conducted a multiple regression analysis showing appraisals to have the strongest association with adjustment, accounting for $12 \%$ variance in anxiety and $34 \%$ variance in depression. Being provided with a confidential psychological space to promote positive reinterpretation and alternative appraisals meant that Theresa was able to dynamically select a coping strategy using 'best fit' to meet her appraisal/stress demand in the individual situations she encountered. This promoted her sense of cognitive agency, increased her sense of control and resilience, supported and integrated her SCI with her self-concept and, in turn, facilitated her psychological adjustment.

Alongside this, a key point from this case, and significant consideration for future research, is the impact that negative perceptions and unconscious cognitive bias can have on adjustment after SCI. Negative perceptions of disability are commonplace in the non-injured population. Theresa's presentation shows how these beliefs can have a significant negative effect on initial perception after injury, with assumptions being made about value, purpose and usefulness of one's life based on these. Olver and Duff matched SCI individuals with non-SCI individuals and found that people without SCI consistently predicted lower quality, value and meaning of life for people with SCI compared to their own [39]. The implications of such negative perceptions and assumptions of disability are poignant and extremely relevant for people who are newly injured, their families, rehabilitation staff and wider society. 
Providing education and awareness-raising within noninjured community members, including friends and relatives of people living with SCI, is a crucial and sometimes neglected element of rehabilitation, and one that peer mentors within SCIC rehabilitation can positively influence. Although most UK SCI Centres provide psychoeducational family days, there is more that can be done at a societal level to provide education around disability. Including books such as 'The Adventures of Grandad Wheels' as a part of mainstream reading education can be effective in reducing community taboo [40].

The case study demonstrates the complexity of SCI rehabilitation and the interconnected MDT approach to psychological treatment. Although application of the appraisal-based model and associated intervention was a part of structured psychological therapy, this was provided within a backdrop of complimentary intervention by others such as nursing teams, physiotherapy, occupational therapy, medical input and in Theresa's case speech and language therapy with MDT goal planning connecting psychological goals [26] within overall BA and rehabilitation outcomes [41]. Theresa was supported in attending groups to aid communication, socialisation with other individuals with SCI and peer mentoring. Successful adjustment to SCI requires a collaborative MDT approach, with progress being interconnected with improvement in other therapies. During Theresa's psychological treatment sessions, discussions were focused around verbal independence and goal setting however, the real-life application of this was only able to be behaviourally applied with support from the nursing and therapy team. This highlights the significance of collaborative across-team working in order to achieve optimal psychological and physical adjustment following SCI.

Acknowledgements The authors would also like to thank Theresa for permission to share her story and members of the MDT who provide a collaborative service offering individuals optimal rehabilitation.

\section{Compliance with ethical standards}

Conflict of interest The authors would like it to be known that Theresa is a pseudonym used to maintain anonymity. Written consent was gained from the individual detailed for her case to be used in an ISCoS Scientific Meeting oral presentation (2019) and in this written publication (2020).

Publisher's note Springer Nature remains neutral with regard to jurisdictional claims in published maps and institutional affiliations.

\section{References}

1. Martz E, Livneh H, Priebe M, Wuermser LA, Ottomanelli L. Predictors of psychosocial adaptation among people with spinal cord injury or disorder. Arch Phys Med Rehabilit. 2005;86:1182-92.

2. Pollard C, Kennedy P. A longitudinal analysis of emotional impact, coping strategies, and post-traumatic, psychological growth following spinal cord injury: a 10-year review. Br J Health Psychol. 2007;12:347-62.

3. Kennedy P, Rogers BA. Anxiety and depression after spinal cord injury: a longitudinal analysis. Arch Phys Med Rehabilit. 2000;81:932-7.

4. Fitchenbaum J, Kirshblum S. Psychologic adaptation to spinal cord injury. In: Kirshblum S, Campagnola DI, DeLisa JA, editors. Spinal cord medicine. Philadelphia: Lippensott, Williams and Wilkins; 2002.

5. Lazarus RS, Folkman S, editors. Stress, appraisal and coping. New York: Springer; 1984.

6. Buckelew SP, Frank RG, Elliott TR, Chaney J, Hewett J. Adjustment to spinal cord injury: stage theory revisited. Paraplegia. 1991;29:125-30.

7. Duff J, Kennedy P. Spinal cord injury. In: Llewelyn S, Kennedy P, editors. Handbook of clinical health psychology. Chichester: John Wiley \& Sons Ltd; 2003. p. 251-75.

8. Folkman S, Lazarus RS, Gruen R, DeLongis A. Appraisal, coping, health status and psychological symptoms. J Personal Soc Psychol. 1986;50:571-9.

9. Skinner E, Edge K, Altman J, Sherwood H. Searching for the structure of coping: a review and critique of category systems for classifying ways of coping. Psychol Bull. 2003;129:216-69.

10. King C, Kennedy P. Coping effectiveness training for people with spinal cord injury: preliminary results of a controlled trial. $\mathrm{Br} \mathrm{J}$ Clin Psychol. 1999;38:5-14.

11. Chesney MA, Chambers DB, Taylor JM, Johnson LM, Folkman S. Coping effectiveness training for men living with HIV: results from a randomized clinical trial testing a group-based intervention. Psychosom Med. 2003;65:1038-46.

12. Kennedy P, Duff J, Evans M, Beedie A. Coping effectiveness training reduces depression and anxiety following traumatic spinal cord injuries. Br J Clin Psychol. 2003;42:1-52.

13. Kennedy P, Kilvert A, Hasson L. A 21-year longitudinal analysis of impact, coping, and appraisals following spinal cord injury. Rehabilit Psychol. 2016;61:92-101.

14. Middleton J, Craig C. Psychological challenges in treating persons with spinal cord injury. In Craig A, Tran Y (Eds.). Psychological dynamics associated with spinal cord injury rehabilitation: New directions and best evidence. New York: Nova Science Publishers, 2008.

15. Kennedy P, Evans M, Sandhu N. Psychological adjustment to spinal cord injury: the contribution of coping, hope and cognitive appraisals. Psychol Health Med. 2009;14:17-33.

16. Wineman NM, Durand EJ, Steiner RP. A comparative analysis of coping behaviors in persons with multiple sclerosis or a spinal cord injury. Res Nurs Health. 1994;17:185-94.

17. Kennedy P, Lude P, Elfström ML, Smithson E. Appraisals, coping and adjustment pre and post SCI rehabilitation a 2-year follow-up study. Spinal Cord. 2012;50:112-8.

18. NICE. Generalised anxiety disorder and panic disorder in adults: management. 2011. https://www.nice.org.uk/guidance/CG113/cha pter/1-Guidance.

19. NICE. Depression in adults: recognition and management. 2016. https://www.nice.org.uk/guidance/CG90.

20. Craig A, Hancock K, Dickson H, Chang E. Long-term psychological outcomes in spinal cord injured persons: results of a controlled trial using cognitive behavior therapy. Arch Phys Med Rehabilit. 1997;78:33-38.

21. Dorstyn DS, Mathias JL, Denson LA. Psychological intervention during spinal rehabilitation: a preliminary study. Spinal Cord. 2010;48:756-61. 
22. Mehta S, et al. An evidence-based review of the effectiveness of cognitive behavioral therapy for psychosocial issues post-spinal cord injury. Rehabilit Psychol. 2011;56:15-25.

23. Dorstyn D, Mathias J, Denson L. Efficacy of cognitive behavior therapy for the management of psychological outcomes following spinal cord injury a meta-analysis. J Health Psychol. 2011;16:374-91.

24. Kennedy P. Coping effectively with spinal cord injuries; a group programme workbook. Treatments that work series. Oxford: Oxford University Press; 2009.

25. Craig A, Middleton J, Duff J. (accepted for publication). Spinal Cord Injuries, $\mathrm{p} \mathrm{X}$ in vol $\mathrm{X}$. In: Comprehensive Clinical Psychology. Elsevier Science Ltd.

26. Kennedy P, Henderson J, Gallagher S. Improving goal attainment with spinal cord injured patients. J Assoc Qual Healthc. 1996;3:145-5.

27. Dean RE, Kennedy P. Measuring appraisals following acquired spinal cord injury: a preliminary psychometric analysis of the appraisals of disability. Rehabilit Psychol. 2009;54:222-31.

28. Zigmond AS, Snaith RP. The hospital anxiety and depression scale. Acta Psychiatr Scand. 1983;67:361-70.

29. Kennedy P, Scott-Wilson U, Sandhu N. The psychometric analysis of a brief and sensitive measure of perceived manageability. $\mathrm{J}$ Psychol Health Med. 2009; 14:454-65.

30. Bjelland I, Dahl AA, Haug TT, Neckelmann D. The validity of the hospital anxiety and depression scale. Update Lit Rev J Psychosom Res. 2002;52:69-77.

31. Wolstenholme D, Downes T, Leaver J, Partridge R, Langley J. Improving self-efficacy in spinal cord injury patients through "design thinking" rehabilitation workshops. BMJ Qual Improv Rep. 2014;3:1-5.
32. Duff J. NSIC Stoke Mandeville SCI Psychological health and wellbeing matched care intervention pathway. UK Copyright Service Registration: 284734611 (2017).

33. NICE guideline. 2018. www.nice.org.uk/guidance/ng116.

34. Hofmann SG, Sawyer AT, Witt AA, Oh D. The effect of mindfulness-based therapy on anxiety and depression: a metaanalytic review. J Consult Clin Psychol. 2010;78:169-83.

35. Lewinsohn PM. The behavioral study and treatment of depression. In: Hersen M, Eisler RM, Miller PM, editors. Progress in behavioral modification. New York: Academic; 1975. p. 19-65.

36. Hatch R, Young D, Barber V, Griffiths J, Harrison DA, Watkinson P. Anxiety, depression and post traumatic stress disorder after critical illness: a UK-wide prospective cohort study. Crit Care. 2018; 22.

37. Gillett JL, Duff J, Eaton R, Finlay K. Psychological outcomes of MRSA isolation in spinal cord injury rehabilitation. Spinal Cord Ser Cases. 2020;6:63-72.

38. Kennedy P, Lowe R, Grey N, Short E. Traumatic spinal cord injury and psychological impact: a cross-sectional analysis of coping strategies. Br J Clin Psychol. 1995;34:627-39.

39. Olver L, Duff J. Cited in: Duff J, Kennedy P. Spinal cord injury. In: Llewelyn S, Kennedy P (eds.). Handbook of clinical health psychology. Chichester: John Wiley \& Sons Ltd; 2003. p. 251-75.

40. Abram B. The adventures of grandad wheels. United Kingdom: Independent Publishing Network; 2019.

41. Duff J. Rehabilitation and goal planning approaches following spinal cord injury: facilitating adjustment. In: Craig A, Tran Y, editors. Psychological aspects associated with spinal cord injury rehabilitation: new directions and best evidence. New York: Nova Science; 2008. 